\title{
H89 dihydrochloride hydrate and calphostin C lower the body temperature through TRPV1
}

\author{
DONGYAN BAO, WENQING ZHAO, CONGCONG DAI, HONGMEI WAN and YU CAO \\ Department of Physiology, China Medical University, Shenyang, Liaoning 110000, P.R. China
}

Received April 20, 2017; Accepted October 31, 2017

DOI: $10.3892 / \mathrm{mmr} .2017 .8078$

\begin{abstract}
The transient receptor potential vanilloid (TRPV1) serves as a negative regulator of body temperature, and during fever conditions its expression can lead to a decrease in temperature. TRPV1 is regulated by a variety of enzymes; however, it is currently unclear whether the regulation of TRPV1 phosphorylation may serve a role in the increase in TRPV1 expression during fever. In the present study, using an in vivo experimental method, rat brain ventricles were injected with the protein kinase A (PKA) antagonist, H89, and the protein kinase $\mathrm{C}$ (PKC) antagonist, calphostin $\mathrm{C}$, and fever was induced using lipopolysaccharide (LPS) in order to detect the expression of TRPV1 and phosphorylated (p-)TRPV1, the intracellular $\mathrm{Ca}^{2+}$ concentration $\left[\left(\mathrm{Ca}^{2+}\right)_{\mathrm{i}}\right]$ of hypothalami and rat body temperature. The results demonstrated that following the generation of fever using LPS, the expressions of TRPV1 and p-TRPV1, and hypothalamic $\left[\mathrm{Ca}^{2+}\right]_{\mathrm{i}}$ markedly increased. In addition, following an injection with the PKA or PKC antagonist, the temperature increased further due to the inhibition of p-TRPV1. Thus, it was hypothesized that PKA and PKC may be involved in TRPV1 phosphorylation, resulting in a temperature reduction during LPS-induced fever conditions.
\end{abstract}

\section{Introduction}

Fever is a reaction of the body to infection or inflammation (1). On the one hand, it is beneficial to the body, because it activates the immune system and accelerates the anabolism, which is conducive to killing bacteria and viruses (1-3). On the other hand, it is harmful to the body, because it causes the heart to beat faster-10 pulses/min more with every increase of $1^{\circ} \mathrm{C}$, resulting in an additional burden on the heart. High fever also causes cell degeneration, resulting in multi-organ dysfunction. Paracetamol (4,5), a common febrifuge at present, is the first

Correspondence to: Mrs. Yu Cao, Department of Physiology, China Medical University, $77 \mathrm{Pu}$ Road, Shenbei, Shenyang, Liaoning 110000, P.R. China

E-mail: caoy5955@sina.com

Key words: transient receptor potential vanilloid 1, fever, H89, calphostin synthetic febrifuge with preferred effects on lowering the temperature (6). But for patients with long-term fever (2 weeks or more), there is a lack of evidence for safety with long-term use of paracetamol (7-9). In addition, long-term fever is difficult for the human body to tolerate and causes great discomfort to the patient. At present in clinical applications, certain febrifuges work slowly with a short action time, resulting in recurring conditions; and some febrifuge treatments work fast, but with many side-effects (9). Studies on antipyretic mechanisms are beneficial for the development of new febrifuges to provide clinical fever patients with more effective treatments.

In 1949, Dubois (10) posed the question 'Why are fever temperatures over $41^{\circ} \mathrm{C}$ rare?' It is indicated that the body also starts a mechanism to limit the fever range during a rising temperature in order to prevent irreversible damage. Endogenous temperature negative regulators already discovered include lipoprotein 1 (11), arginine vasopressin (AVP) (11) and the melanocyte-stimulating hormone (MSH) (11). They gradually increase during a rising temperature and play a role in the control of the temperature.

In 1997, Caterina et al (12) successfully cloned a receptor that can be activated by capsaicin (a derivative of vanilloids). Therefore, transient receptor potential vanilloid (TRPV1) was also called a capsaicin receptor or vanillic acid receptor. It is a non-selective cation channel that mainly results in the flow of $\mathrm{Ca}^{2+}$. Under in vitro experimental conditions, it can be activated by a variety of physical and chemical factors, which mainly include capsaicin, heat greater than $43^{\circ} \mathrm{C}$ and protons [e.g., acid ( $\mathrm{pH}<5.3)](12,13)$. TRPV1 is associated with various sensory functions and its temperature-sensitive property has attracted increasing attention (14-18).

In recent years, it has been revealed that several TRPV1 inhibitors can cause fever (16-18), and further studies on analgesic effects of TRPV1 channel protein have been conducted. Human bodies also display an obvious and reversible increase of temperature $(14,19)$ through the use of the TRPV1 inhibitor AMG517 or ABT-102, which has been confirmed by clinical experiments. In 1984, Hori (20) found that rodents or humans showed temperature reduction through the use of capsaicin (now determined as a TRPV1 activator). As has been suggested in recent studies, mice with knock-out of TRPV1 do not show temperature reduction through the use of TRPV1 activators $(18,21)$. There is still much confusion about the physiological functions and pathophysiological mechanisms of TRPV1, which makes more profound and wider research 
required. Studies have reported that the TRPV1 channel in internal organs also continues to send signals of a reducing temperature in order to regulate the temperature $(22,23)$.

TRPV1, generally considered to be a pathological receptor, participates in pain transmission in many diseases and noxious stimulation $(24,25)$, as it is a proinflammatory factor. Recent studies, however, have suggested that in some diseases, TRPV1 also plays a protective role for the body $(26,27)$, such as its protection of the cardiovascular system and the gastrointestinal system. Besides, TRPV1 also plays a part in normal physiological functions (19), such as the adjustment of bladder functions (28), the regulation and control of temperature and neurogenesis in case of a healthy physiology (29). The incompatible roles of TRPV1 in different diseases require us to conduct further research to better support the clinical services.

The TRPV1 functions are regulated by many protein kinases, such as protein kinase A (PKA) (30-32), MAPK and protein kinase C (PKC) (33-36), PKD and CaMKII (36), PI3K and Cdk5 (37,38). As early as 1996, Cesare and Mcnaughton discovered that PMA (phorbol ester, a PKC agonist) activated TRPV1 by PKC in dorsal root ganglion (DRG) cells (39), and that the translocation of PKC $\varepsilon$ to DRG cell membranes increased the sensitivity of TRPV1 channel currents (40). Phosphorylation of TRPV1 mediated by PKC participates in hyperalgesia and diabetic neuropathy $(41,42)$. Phosphorylation mediated by PKC regulates and controls TRPV1 channel currents (35), and temperature sensitivity of TRPV1, possibly by lowering the activated temperature threshold values of TRPV1 $(35,43)$. As has been reported in vitro studies, cAMP-dependent PKA can phosphorylate TRPV1. Bhave et al found that PKA regulated the phosphorylation of TRPV1 in 2002 (30). Shp-1 (acetate phosphatase), an important enzyme in the process of TRPV1 dephosphorylation, can cause TRPV1 dephosphorylation in DRG cells, and then inhibit pain caused by the activation of TRPV1 by algogenic substances (43), but this is limited to in vitro experiments. The environment in vivo is more complex with a variety of influence factors. How does phosphorylation influence TRPV1 during its regulation of the temperature?

\section{Materials and methods}

Ethical approval. Specific pathogen-free Sprague Dawley rats were obtained from the Department of Laboratory Animals of China Medical University (CMU; Shenyang, China) (license no. SCXK Liaoning 2013-0007). All experiments were performed at CMU in accordance with the National Institute of Health (NIH) Guidelines for the Care and Use of Laboratory Animals. The protocol for animal handling and the treatment procedures were approved by the CMU Animal Care and Use Committee.

\section{Animal treatment and experiment grouping}

Fever animal models caused by lipopolysaccharide (LPS). All animal experiments were performed according to the recommendations of IASP, the NIH Guide for Care and Use of Laboratory Animals, and were approved by the Animal Ethics Committee of China Medical University. All efforts were made to minimize the number of animals used and their suffering.
The experimental animals were randomly divided into the fever-caused-by-LPS group (LPS group) and the control group. The abdominal cavities of the rats in the LPS group were injected with $80 \mu \mathrm{g} / \mathrm{kg}$ of LPS (4 ml/kg) (L2630; Sigma-Aldrich; Merck KGaA, Darmstadt, Germany) diluted with a stroke-physiological saline solution. A real-time monitoring of the temperature changes was carried out. The rats were decapitated and the preoptic/anterior hypothalamus (PO/AH) area tissues were taken out to detect data 2, 3, 4 and $5 \mathrm{~h}$ after the injection. At each time point the data of 5 rats was collected. The abdominal cavities of the rats in the control group were injected with $4 \mathrm{ml} / \mathrm{kg}$ of physiological saline; and the detection of the temperature, the sampling of the $\mathrm{PO} / \mathrm{PH}$ area tissues and others were all performed as with the LPS group.

The application of PKA inhibitors on fever animals caused by LPS. The animals' treatment and grouping were as follows (n=5): i) The control group: $10 \mu \mathrm{l}$ double distilled water prepared with H89 (a PKA inhibitor) (B1427; Sigma-Aldrich; Merck KGaA) was injected into the lateral ventricles; and physiological saline of $4 \mathrm{ml} / \mathrm{kg}$ prepared with LPS was injected into the abdominal cavities after $0.5 \mathrm{~h}$. ii) The LPS group (L group): $80 \mu \mathrm{g} / \mathrm{kg}$ (4 ml/ $\mathrm{kg}$ ) of LPS prepared with physiological saline was injected into the abdominal cavities $0.5 \mathrm{~h}$ after $10 \mu \mathrm{l}$ of double distilled water was injected into the lateral ventricles. iii) The LPS+PKA inhibitor (H89) group was divided into 3 dose groups: The LH1, LH2 and LH3 groups: $10 \mu \mathrm{l}$ of $\mathrm{H} 89$ (prepared with double distilled water) of different concentrations was injected into the lateral ventricles: $0.5,1$ and $1.5 \mu \mathrm{g} /$ site of the LH1 group, LH2 group and LH3 group respectively. LPS (the same previous dose) was injected into the abdominal cavities after $0.5 \mathrm{~h}$. iv) The PKA inhibitor group (H1, H2 and $\mathrm{H} 3$ groups): $10 \mu \mathrm{l}$ of $\mathrm{H} 89$ of the above 3 concentrations were injected into the lateral ventricles in respectively the H1, H2 and H3 groups; and physiological saline of $4 \mathrm{ml} / \mathrm{kg}$ was injected into the abdominal cavities after $0.5 \mathrm{~h}$.

During the experiment temperature changes were monitored. The animals in all groups were decapitated after $4.5 \mathrm{~h}$ and the $\mathrm{PO} / \mathrm{AH}$ area tissues in the hypothalamus were taken out.

The application of PKC inhibitor on feverous animals caused by LPS. The animals' treatment and grouping were as follows $(n=5)$ : i) The control group: Calphostin C (PKC inhibitor, cal) (C6303; Sigma-Aldrich; Merck KGaA) $10 \mu$ l prepared with DMSO was injected into the lateral ventricles, and physiological saline of $4 \mathrm{ml} / \mathrm{kg}$ was injected into the abdominal cavities after $0.5 \mathrm{~h}$. ii) The LPS group: $10 \mu \mathrm{l}$ of DMSO was injected into the lateral ventricles and LPS of $80 \mu \mathrm{g} / \mathrm{kg}(4 \mathrm{ml} / \mathrm{kg})$ prepared with physiological saline was injected into the abdominal cavities after 0.5 h. iii) The LPS+PKC inhibitor (cal) group (LPS+cal group): $10 \mu \mathrm{l}$ of $200 \mathrm{ng} /$ site cal (calphostin C, a PKC inhibitor) prepared with DMSO was injected into the lateral ventricles, and LPS of the same previous dose was injected into the abdominal cavities after $0.5 \mathrm{~h}$. iv) The PKC inhibitor group (cal group): $10 \mu \mathrm{l}$ of cal (the same dose as above) was injected into the lateral ventricles, and physiological saline of $4 \mathrm{ml} / \mathrm{kg}$ was injected into the abdominal cavities after $0.5 \mathrm{~h}$.

During the experiment the temperature changes were monitored. The animals in all groups were decapitated after $4.5 \mathrm{~h}$ and the $\mathrm{PO} / \mathrm{AH}$ area tissues in the hypothalami were taken out. 
In vivo implantation of telemetering temperature transmitters and measurement of the temperature. The telemetering temperature transmitters (transmitter model, no. TA-F40; Sichun Taimeng Company, China) used to measure body temperature look like capsules of approximately $1 \mathrm{~cm}$ in length with suture holes. After being placed in the abdominal cavity by surgery, the signal it emits can be received by the instrument in vitro. It can be set to receive the signal every 5 or $10 \mathrm{~min}$. By means of it the animal's body temperature could be determined.

Telemetering temperature transmitters were implanted into the rats' abdominal cavities under anesthesia and fixed on the abdominal walls. The abdominal cavities were then closed. The animals were caged after the surgery, fed separately and used for experiments after 1 week of recovery.

The rat temperature was measured with the BW-200 physiological wireless telemetry system. The rats' basal temperature was recorded from 8:00 a.m. to 2:00 p.m. 1 day before the experiment at a measuring interval of $5 \mathrm{~min}$. The average value of the temperature during this period was recorded as the basal temperature.

During the experiment, the temperature was automatically recorded once every $5 \mathrm{~min}$ until the end of the experiment. The curves of temperature changes were traced.

Intubation of the rats' lateral ventricle. The rats' heads were fixed on stereotaxic apparatuses to expose the anterior fontanelle after an intraperitoneal injection of $10 \%$ chloral hydrate and $25 \%$ urethane $(1: 1)$. Holes were drilled at $0.8 \mathrm{~mm}$ behind the coronal suture of the skull surface and $1.5 \mathrm{~mm}$ lateral to the sagittal suture per rat brain atlas. A guiding catheter with an external diameter of $1 \mathrm{~mm}$ was used to insert into one lateral ventricle at a depth of $4.0 \mathrm{~mm}$, and fixed with liquid for denture acrylic mixed with dental cement. The animals were caged after the operation, fed separately and used to perform the experiment after 1 week of recovery.

The use of western blotting to detect the expression levels of TRPV1 and phosphorylated (p-)TRPV1 in the hypothalamic $P O / A H$ area. The rats' hypothalamic tissues were taken out and precooling membrane lysate was added to extract membrane proteins, which were crushed with a homogenizer and ultrasound in an ice bath, and centrifugated at $4^{\circ} \mathrm{C}$ with $14,486 \mathrm{~g}$ for $60 \mathrm{~min}$ to obtain the supernatant. The concentrations of proteins in the samples were assayed with a spectrophotometer (phenol reagent method). The buffer was added into the protein extract to dilute all samples into the same concentration. The proteins were separated with SDS-polyacrylamide gel electrophoresis (SDS-PAGE, 10\% separation gel and 4\% stacking gel) under a voltage of $120 \mathrm{~V}$. The gel was taken out and electrotransfered to PVDF film. The film was washed with TTBS for several times, then placed in sealing liquid (TTBS containing 10\% skimmed milk powder), and sealed at room temperature for 1-2 h. It was washed with TTBS for 3 times, with each washing time amounting to $5 \mathrm{~min}$. Such samples were added with the first antibody for overnight, i.e., the TRPV1 mouse anti-rat monoclonal antibody $(1: 1,000)$ (BA2589, polyclonal antibody; Boshide, Wuhan, China) or the p-TRPV1 rabbit anti-rat polyclonal antibody $(1: 1,000)$ (PAB8499, polyclonal antibody; Abnova, Taipei, Taiwan). The film was washed with TTBS 3 times, with each washing time amounting to $5 \mathrm{~min}$, and the second antibody (1:500) labeled with horseradish peroxidase (HRP) was added to the sample, after which it was incubated at room temperature for $2 \mathrm{~h}$. The PVDF film was taken out and washed with TTBS 3 times, with each washing time amounting to $5 \mathrm{~min}$; color-developing was carried out with enhanced chemiluminescence (ECL), and a gel imaging and image analysis system was used to analyze. Anti $\beta$-actin antibodies were used in the control group. The gray level ratios between TRPV1 or p-TRPV1 and the corresponding $\beta$-actin proteins were the relative expressions of TRPV1 or p-TRPV1.

The assay of the content of PKA and PKC in cells of the PO/AH area. Phosphate-buffered saline (PBS; $1 \mathrm{ml}, \mathrm{pH} 7.4$ ) was added into the removed tissues of the PO/AH area in the iced bath, which was prepared as tissue homogenate with a homogenizer, and was centrifugated with 1,958 $\mathrm{g}$ for $20 \mathrm{~min}$. Consequently, the supernatant was taken out and put at $-20^{\circ} \mathrm{C}$ for the spare. The procedures were performed in accordance with the instruction sheet of the test kit for PKA and PKC enzyme-linked immunosorbent assay. The content of PKA (H233-1) was expressed with (ng/ml), and the content of PKC (H233-2; both from Nanjing Jiancheng Bioengineering Institute, Nanjing, China) was expressed with (pmol/l).

The assay of the concentration of intracellular calcium $\left[\left(\mathrm{Ca}^{2+}\right)\right]_{i}$ in the PO/AH area. At corresponding time points, all experimental animals in each group were immediately decapitated to remove their brains, of which the hypothalamic tissues were taken out within $1 \mathrm{~min}$ and immediately placed in $4^{\circ} \mathrm{C}$ D-Hanks solutions and cut into pieces after 2 times of washing. They were added with Hanks balanced salt (HBS) solutions to $2 \mathrm{ml}$ and $0.25 \%$ of concentration of pancreatic enzymes $2 \mathrm{ml}$, and digested in a $37^{\circ} \mathrm{C}$ thermostatic water bath for $45 \mathrm{~min}$, during which samples were blown and beat gently. Then the $4^{\circ} \mathrm{C}$ D-Hanks solutions (containing $10 \%$ calf serum) $3 \mathrm{ml}$ were added into the samples to end the digestion and passed through a 200-mesh sieve and filtrated in a small beaker. The filtrate was centrifugated at $201 \mathrm{~g}$ for 2 times, with each time amounting to $8 \mathrm{~min}$. After removing the supernatant, the precipitate was added with the D-Hanks solutions to prepare the $10^{6}-10^{7} \mathrm{ml}^{-1}$ of the cell suspension. The Trypan blue exclusion test was used for determination, and the cell survival probability ought to be be above $95 \%$ and only in this way it could be tested.

The dual-wavelength spectrophotometer (F-4500 model; Hitachi, Ltd., Tokyo, Japan) was used to assay, with the excitation wavelength being 340 and $380 \mathrm{~nm}$, and the emission wavelength being $510 \mathrm{~nm}$. $\left(\mathrm{Ca}^{2+}\right)_{\mathrm{i}}$ could be calculated on the basis of the following formula. $\left(\mathrm{Ca}^{2+}\right)_{\mathrm{i}}=\mathrm{Kdx}$ (R - Rmin)/(Rmax - R) x F2min/F2max (nmol/l). The Kd value was $224 \mathrm{nmol} \cdot \mathrm{l}^{-1}$, $\mathrm{R}$ was the fluorescence value, and $\left(\mathrm{Ca}^{2+}\right)_{\mathrm{i}}$ was nmol/1. F2min was the measured fluorescence value after adding EGTA and F2max was the measured fluorescence value after adding TritonX-100.

Statistical treatment. The gray level value was analyzed and read by means of image $\mathbf{J}$ image-processing software after the scanning western blot bands. The relative expressions of the 


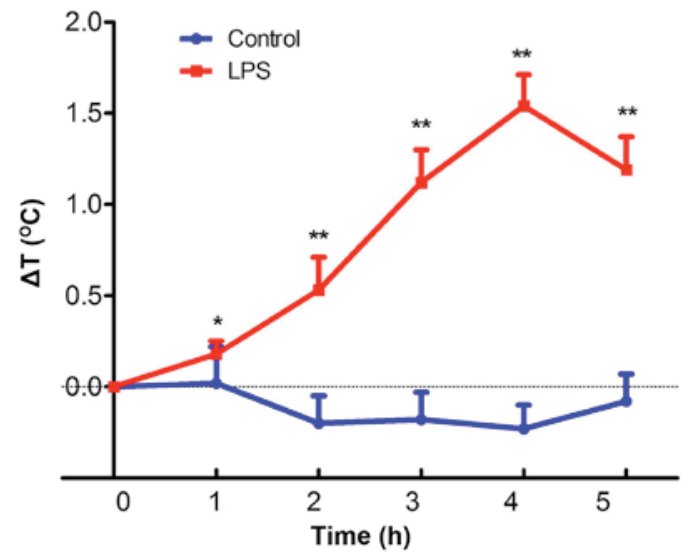

Figure 1. Effect of LPS on rat body temperature. Changes in body temperature were measured using a transmitter. An increase in temperature could be achieved via an intraperitoneal injection of LPS in rats. The temperature reached its peak at $4 \mathrm{~h}$. Data are presented as the mean \pm standard deviation. ${ }^{*} \mathrm{P}<0.05$ and ${ }^{* *} \mathrm{P}<0.01$ vs. control. LPS, lipopolysaccharide.

target proteins were expressed by the ratios of the gray level value between the target proteins and $\beta$-actin. After the drug application, the SPSS two-factor variance analysis method was used to compare the temperature changes among the samples; the SPSS independent-sample t-test was employed to compare the temperature changes between the two samples; the temperature changes among multiple samples were compared with the SPSS one-factor variance analysis method. $\mathrm{P}<0.05$ suggested that the differences had a statistical significance. All experimental data were expressed with the mean \pm standard deviation (SD). SPSS software was used to calculate correlative coefficients and regression equations for linear correlation and linear regression analyses. The experiment was repeated at least 3 times in each group.

\section{Results}

Significant upregulation of TRPV1, p-TRPV1 and $\left(\mathrm{Ca}^{2+}\right)_{i}$ in the hypothalamic PO/AH area after LPS-caused fever. Fig. 1 shows the curves of the values of temperature $\left(\Delta \mathrm{T},{ }^{\circ} \mathrm{C}\right)$ changing with time in all groups. There was no obvious fluctuation in temperature with the rats in the control group during the real-time temperature monitoring. An intraperitoneal injection of LPS in rats can make the temperature rise, peak at $4 \mathrm{~h}$, and then begin to decline.

Expressions of TRPV1 and p-TRPV1 were detected with western blotting in the $\mathrm{PO} / \mathrm{AH}$ area tissues at each time point after the injection with LPS. Fig. 2 displays the expressions of TRPV1 and p-TRPV1 detected by western blotting in the $\mathrm{PO} / \mathrm{AH}$ area tissues at different phases of temperature rising in each experimental group. The expressions of TRPV1 and $\mathrm{p}$-TRPV1 increase in the LPS group as the temperature rises. All expression levels of TRPV1 and p-TRPV1 reach peak values when the temperature is reaches the peak values, and then they both decline.

Fig. 3 shows $\left(\mathrm{Ca}^{2+}\right)_{i}$ in the PO/AH area assayed in the control group and the LPS group at different time points. After LPS causes fever in the rats, $\left(\mathrm{Ca}^{2+}\right)_{\mathrm{i}}$ in the PO/AH area gradually increases and reaches the highest value as $447.703 \mathrm{nmol} / 1$ at $4 \mathrm{~h}$, thus increased 1.95 times compared to that one in the
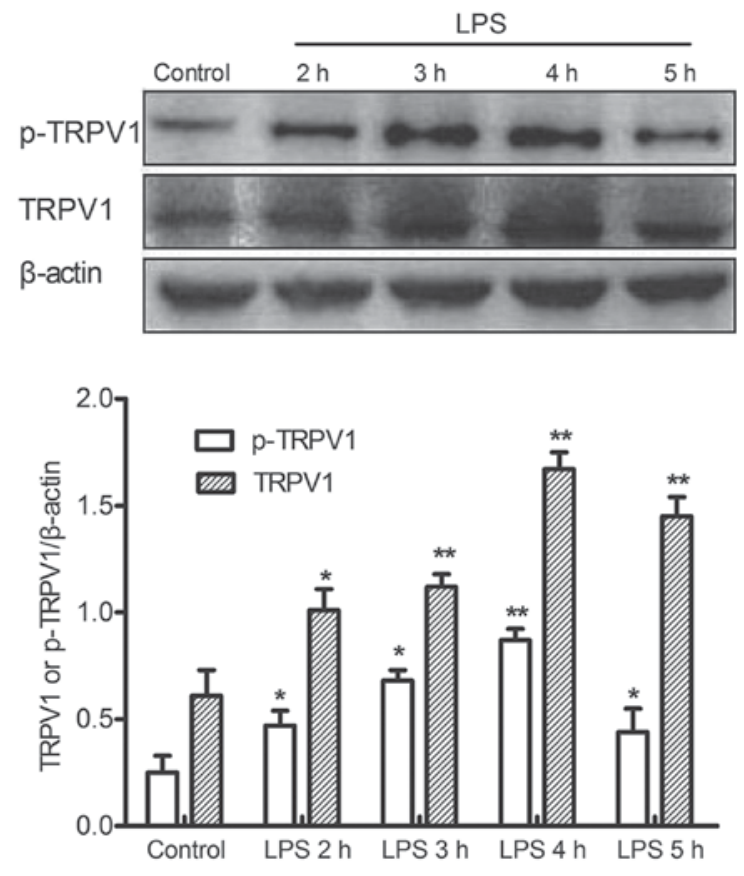

Figure 2. Effect of LPS on the expression of TRPV1 and p-TRPV1 in rats. Western blotting revealed that the expressions of TRPV1 and p-TRPV1 increased with the temperature rising in the LPS group and reached peak values at $4 \mathrm{~h}$. Data are presented as the mean \pm standard deviation. ${ }^{*} \mathrm{P}<0.05$ and ${ }^{* *} \mathrm{P}<0.01$ vs. control. LPS, lipopolysaccharide; TRPV1, transient receptor potential vanilloid; $\mathrm{p}$-. phosphorylated.

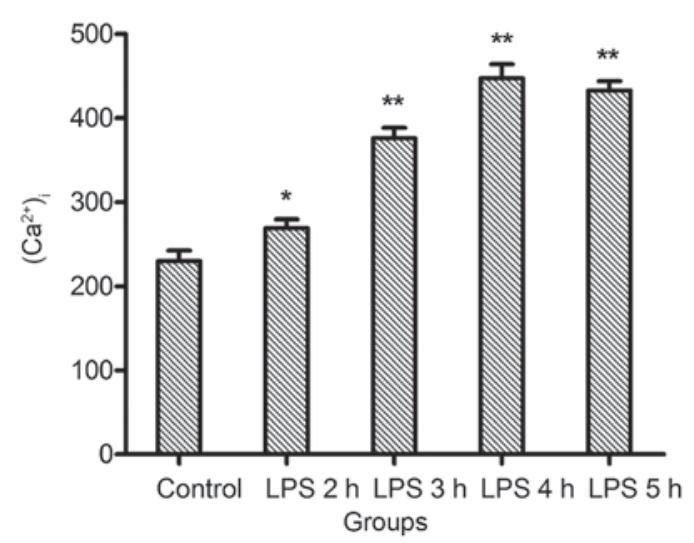

Figure 3. Effects of LPS on $\left(\mathrm{Ca}^{2+}\right)_{\mathrm{i}}$. The highest $\left(\mathrm{Ca}^{2+}\right)_{\mathrm{i}}$ value in the preoptic/anterior hypothalamus area of rats was reached in the LPS group at $4 \mathrm{~h}$. Data are presented as the mean \pm standard deviation. ${ }^{*} \mathrm{P}<0.05$ and ${ }^{* *} \mathrm{P}<0.01$ vs. control. LPS, lipopolysaccharide; $\left(\mathrm{Ca}^{2+}\right)_{\mathrm{i}}$, intracellular $\mathrm{Ca}^{2+}$ concentration.

control group, which is also the highest point the temperature increase will reach. Later $\left(\mathrm{Ca}^{2+}\right)_{\mathrm{i}}$ begins to decline gradually. $\left(\mathrm{Ca}^{2+}\right)_{\mathrm{i}}$ in the LPS group is significantly higher than that in the control group at the 2, 3,4 and $5 \mathrm{~h}$ time points. The change of trends of $\left(\mathrm{Ca}^{2+}\right)_{i}$ were consistent with the change of trends of p-TRPV1 in each group. Fig. 4 is an original detection image record of Fura-2/acetoxymethyl (AM) labeled $\mathrm{Ca}^{2+}$ fluorescence in cells.

PKA inhibitor H89 inhibited TRPV1 phosphorylation by inhibiting PKA to raise the temperature. As is shown in Fig. 5A, the content of PKA in the L group significantly increased, no obvious differences were observed in the comparison of the 


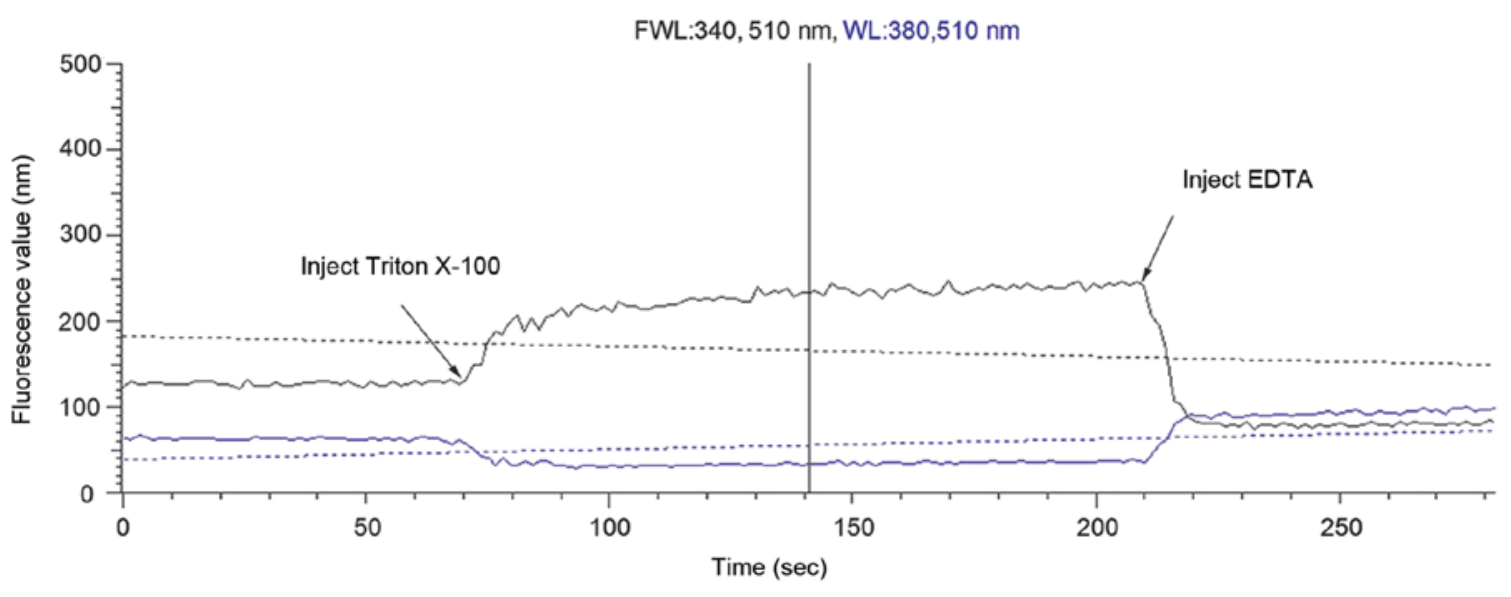

Figure 4. Fura-2/AM labeled fluorescence detection of $\left(\mathrm{Ca}^{2+}\right)_{\mathrm{i}}$ image. The fluorescence values were expressed with ordinates, and the time was expressed with abscissae (sec as unit). The curves in the lower part of the image indicate fluorescence values of Fura- 2 at the excitation wavelength of $380 \mathrm{~nm}$. The curves in the upper part of the image indicate the fluorescence values of Fura- 2 at the excitation wavelength of $340 \mathrm{~nm}$ following its combination with $\mathrm{Ca}^{2+}$ in cells. Triton X-100 was used to break the membrane, and EGTA was applied to bind to calcium and abort the reaction. $\left(\mathrm{Ca}^{2+}\right)_{\mathrm{i}}$, intracellular $\mathrm{Ca}^{2+}$ concentration; AM, acetoxymethyl.

LH1 and the L groups, and the content of PKA in the LH2 and LH3 groups was all lower compared to that one in the LPS group. There were no significant differences in the $\mathrm{H} 1, \mathrm{H} 2$ and normal control group; the content of PKA was lower in the $\mathrm{H} 3$ group in comparison to the one in the normal control group, suggesting that $\mathrm{H} 89$ could effectively inhibit the expression of PKA.

Fig. 5B shows the curves of the rats' temperature changes after the injection in the brain ventricle of PKA inhibitor H89 in all groups. The temperature gradually rises after the intraperitoneal injection of LPS in the rats of the L group, reaches a peak after $4 \mathrm{~h}$, and then begins to decline. The rats temperature changes in LH1 are similar with those in the L group, and no significant differences are observed at all observation time points between them. The rats' temperature is significantly higher in the LH2 group compared to that one in the L group during observation, and is still at a high level at $5 \mathrm{~h}$. The temperature rise is the most obvious in the LH3 group between $3-5 \mathrm{~h}$, and is also still at a high level at $5 \mathrm{~h}$. No obvious temperature rise was noticed in the $\mathrm{H} 1$ and $\mathrm{H} 2$ groups. There was a temperature rise noted in the $\mathrm{H} 3$ group, which was still at a high level at $5 \mathrm{~h}$, but it was lower in comparison with that one in the LH2 and LH3 groups.

Fig. 5C shows the changes of $\left(\mathrm{Ca}^{2+}\right)_{\mathrm{i}}$ in the $\mathrm{PO} / \mathrm{AH}$ area tissue in all experimental groups after the use of the PKA inhibitor $\mathrm{H} 89$; $\left(\mathrm{Ca}^{2+}\right)_{\mathrm{i}}$ significantly rises after fever has been induced with LPS; and the $\left(\mathrm{Ca}^{2+}\right)_{\mathrm{i}}$ rising range decreases with the increase of the H89 dose, under the condition of pre-treatment with H89 before LPS is administered. No statistical differences are revealed in the $\mathrm{H} 1, \mathrm{H} 2$ and normal control groups, and the $\mathrm{H} 3$ group obviously reduces in comparison with the control group. The change trends of $\left(\mathrm{Ca}^{2+}\right)_{\mathrm{i}}$ are consistent with the change trends of p-TRPV1 in each group.

Fig. 6 displays the expression levels of TRPV1 and p-TRPV1 in the $\mathrm{PO} / \mathrm{AH}$ area cells in all experimental groups after the injection of the PKA inhibitor H89 in the rats' lateral ventricles. The expression levels of TRPV1 and p-TRPV1 increase more obviously in the $\mathrm{L}$ group than those in the control group. The expressions of p-TRPV1 show dose-dependent lowering in all the experimental groups through the use of the PKA inhibitor H89, in which no obvious differences are noted in comparison to the low dose LH1 group and the L group. The expressions of p-TRPV1 significantly reduce in the LH2 and LH3 groups as compared with those in the L group. When the simple PKA inhibitor H89 is given, no significant differences of expressions of p-TRPV1 are identified in the low dose $\mathrm{H} 1$ group and the moderate dose $\mathrm{H} 2$ group compared to those in the control group, and an obvious decrease of the expressions of p-TRPV1 is revealed in the high dose $\mathrm{H} 3$ group compared to those in the control group.

The expression levels of TRPV1 are similar in the L, LH1, LH2 and LH3 groups, as they all increase in comparison to those in the control group. There are no significant differences in the expressions of TRPV1 in the H1 and H2 groups compared to those in the control group. The expression levels of TRPV1 increased in the $\mathrm{H} 3$ group, compared to those in the control group.

PKC inhibitor calphostin C inhibited TRPV1 phosphorylation by inhibiting $P K C$ to raise the temperature. In comparison to the content in the normal control group, the content of PKC significantly increased in the tissues of the PO/AH area of the LPS group. The content of PKC was lower in the cal + LPS group compared to that of the LPS group, but was higher than the one in the normal control group. No obvious differences were observed in the single intracerebroventricular injection of the cal group and the normal control group (Fig. 7A).

Compared to the control group, the temperature of the LPS group significantly increased and reached a peak at $4 \mathrm{~h}$, and then began to decline. Meanwhile, the temperature of the rats with lateral ventricle injection of cal (200 $\mathrm{ng} / \mathrm{site})$ was up to a peak at $5 \mathrm{~h}$, which was higher than the temperature in the LPS group with a simple injection of LPS. No obvious changes were noted in the temperature of the rats with a simple injection of cal (Fig. 7B).

$\left(\mathrm{Ca}^{2+}\right)_{\mathrm{i}}$ obviously increased in the LPS group as compared to that one in the normal control group; $\left(\mathrm{Ca}^{2+}\right)_{\mathrm{i}}$ in the cal + LPS group obviously decreased in comparison to the one in the LPS group, but was higher than the one in the normal control group, and no obvious differences were noted in the $\left(\mathrm{Ca}^{2+}\right)_{\mathrm{i}}$ 

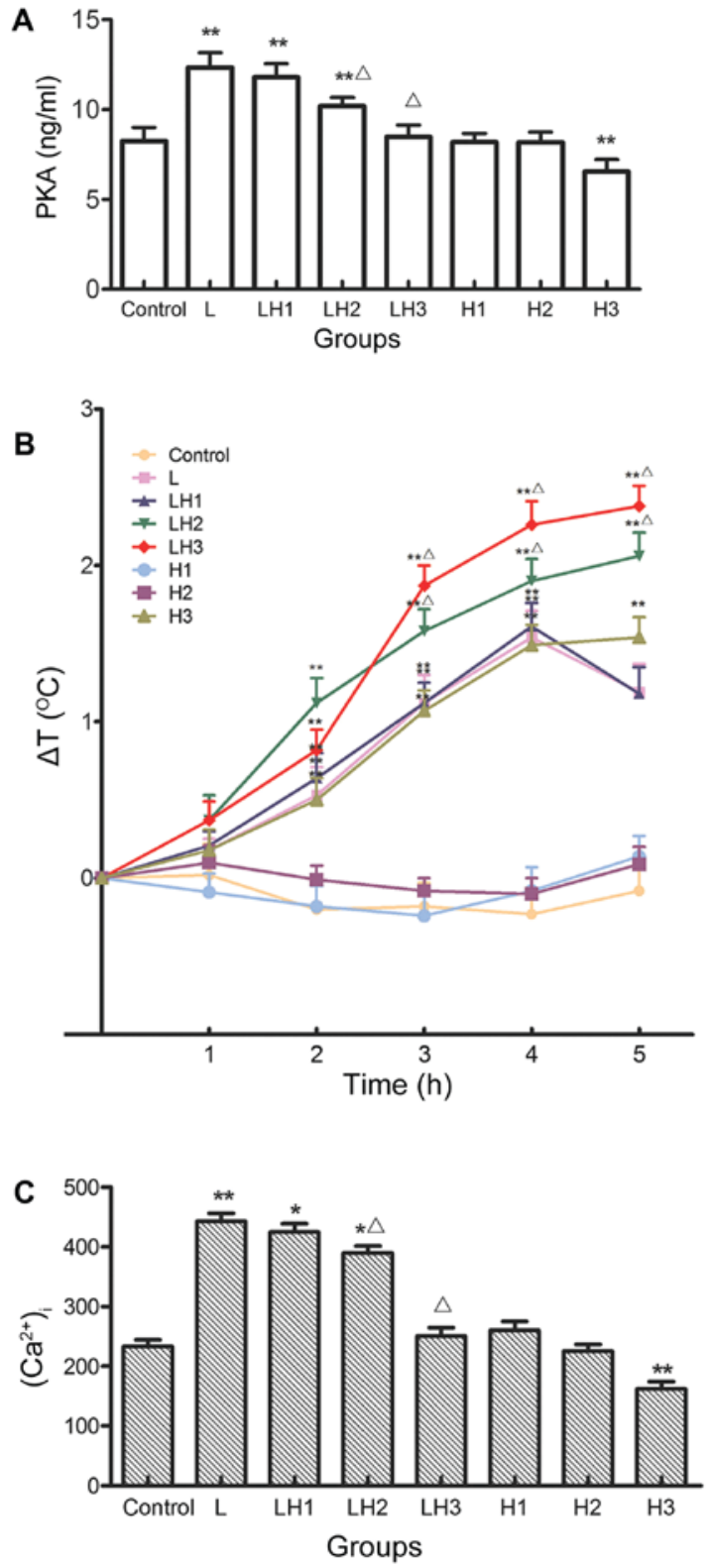

Figure 5. Effect of H89 on rat body temperature, the content of PKA and $\left(\mathrm{Ca}^{2+}\right)_{\mathrm{i}}$. (A) Following $4.5 \mathrm{~h}$ (LPS for $4 \mathrm{~h}$ and $\mathrm{H} 89$ for $4.5 \mathrm{~h}$ ), the PO/AH area was removed from the rats. The content of PKA was monitored using a PKA assay kit. In the LH2 and LH3 groups, the body temperature was lower when compared with that exhibited by the LPS group. In addition, the content of PKA was lower in the $\mathrm{H} 3$ group in comparison with the content observed in the normal control group, suggesting that $\mathrm{H} 89$ can effectively inhibit the expression of PKA. (B) Changes in body temperature following injection. Rat temperature was markedly higher in the LH2 and LH3 groups when compared with the $\mathrm{L}$ group, and it was also significantly increased in the $\mathrm{H} 3$ group. (C) Following $4.5 \mathrm{~h}$ (LPS for $4 \mathrm{~h}$ and $\mathrm{H} 89$ for $4.5 \mathrm{~h}$ ), the PO/AH area was removed from the rats. The rats were administrated with LPS and H89 at the same time, and the $\left(\mathrm{Ca}^{2+}\right)_{\mathrm{i}}$ decreased with the increasing dose of $\mathrm{H} 89$. With a high dose of $\mathrm{H} 89$ in the $\mathrm{H} 3$ group, the $\left(\mathrm{Ca}^{2+}\right)_{i}$ was markedly reduced when compared with the control group. Data are presented as the mean \pm standard deviation. ${ }^{*} \mathrm{P}<0.05$ and ${ }^{* *} \mathrm{P}<0.01$ vs. control; ${ }^{\Delta} \mathrm{P}<0.01$ vs. $\mathrm{L}$ group. $\mathrm{PKA}$ protein kinase $\mathrm{A} ;\left(\mathrm{Ca}^{2+}\right)_{i}$, intracellular $\mathrm{Ca}^{2+}$ concentration; LPS, lipopolysaccharide; $\mathrm{PO} / \mathrm{AH}$, preoptic/anterior hypothalamus; LH groups, LPS and H89 treatment groups; $\mathrm{H}$ groups, $\mathrm{H} 89$ treatment only groups.

after a simple injection of cal in the lateral ventricles compared to that one in the normal control group; and the change trends of $\left(\mathrm{Ca}^{2+}\right)_{\mathrm{i}}$ were consistent with the change trends of $\mathrm{p}$-TRPV1 (Fig. 7C).
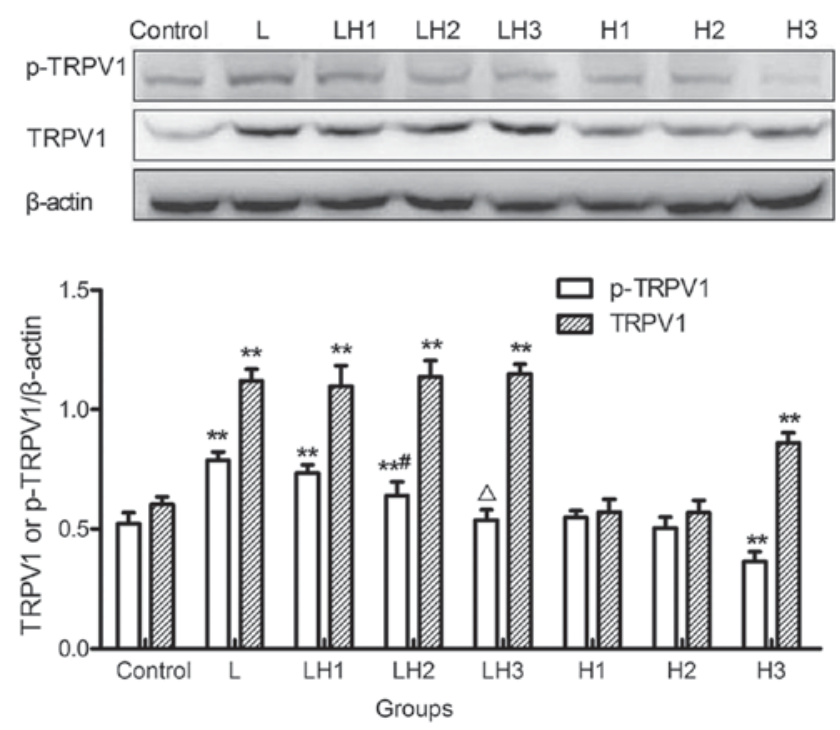

Figure 6. Effect of H89 on rat expression of TRPV1 and p-TRPV1. Following $4.5 \mathrm{~h}$ (LPS for $4 \mathrm{~h}$ and $\mathrm{H} 89$ for $4.5 \mathrm{~h}$ ), the preoptic/anterior hypothalamus area was removed. Western blotting revealed that p-TRPV1 expression decreased in a dose-dependent manner following the use of the PKA antagonist $\mathrm{H} 89$ and LPS at the same time. Using a high dose of H89 alone induced a significant decrease in p-TRPV1 expression. Data are presented as the mean \pm standard deviation. ${ }^{* *} \mathrm{P}<0.01$ vs. control; ${ }^{\#} \mathrm{P}<0.05$ and ${ }^{\Delta} \mathrm{P}<0.01$ vs. LPS. LPS, lipopolysaccharide; TRPV1, transient receptor potential vanilloid; p-, phosphorylated; LH groups, LPS and H89 treatment groups; H groups, H89 treatment only groups; PKA, protein kinase A.

From Fig. 8, it is revealed that in comparison with those in the LPS group, the expression levels of p-TRPV1 significantly decreased and no significant differences were noted in the expression levels of TRPV1, when the rats' lateral ventricles were pre-treated with the PKC inhibitor calphostin $\mathrm{C}$ before the administration of LPS-caused fever in the LPS + cal group. As compared to those in the control group, the expression levels of TRPV1 and p-TRPV1 showed no obvious differences in the cal group with the administration of calphostin $\mathrm{C}$ alone in the lateral ventricles.

\section{Discussion}

The discovery of TRPV1 provides a new way for the study of temperature physiology. TRPV1, its molecular weight being $95 \mathrm{kDa}$, contains 838 amino acids and 6 transmembrane segments, as was discovered first in the dorsal root ganglia of rats, involving pain afferent (12). When activated, it can make a great deal of $\mathrm{Ca}^{2+}$ internal flow (12), resulting in a $\left(\mathrm{Ca}^{2+}\right)_{\mathrm{i}}$ increase to regulate the physiological functions or pathological mechanisms of the body.

It was discovered that there were TRPV1 expressions in the hypothalamic PO/AH area (44). In view of the temperature-sensitive characteristics of TRPV1, TRPV1 as a negative regulator of temperature regulates temperature changes. The article by Alawi et al (45) suggested that an intraperitoneal injection of $50 \mathrm{mg} / \mathrm{kg}$ TRPV1 inhibitor, AMG 9810, in mice can cause the temperature of the mice to increase, and an intraperitoneal injection of $50 \mathrm{mg} / \mathrm{kg}$ AMG 9810 in mice with knock-out of the TRPV1 gene cannot make the mice's temperature increase. Garami et al (46) discovered that a contraction of the skins and tails' blood vessels, an increase of 

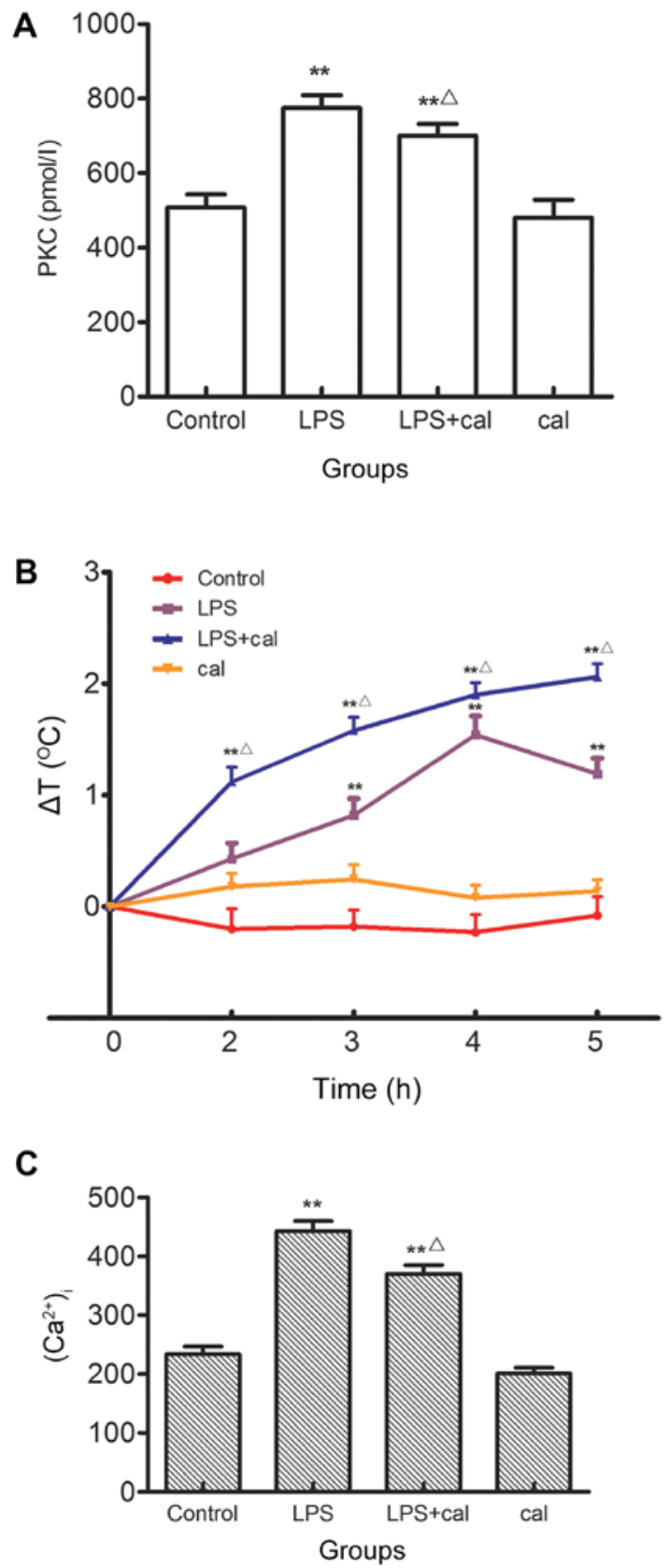

Figure 7. Effect of calphostin $\mathrm{C}$ on rat body temperature, the content of PKC and $\left(\mathrm{Ca}^{2+}\right)_{\mathrm{i}}$. (A) Following $4.5 \mathrm{~h}$ (LPS for $4 \mathrm{~h}$ and calphostin $\mathrm{C}$ for $4.5 \mathrm{~h}$ ), the $\mathrm{PO} / \mathrm{AH}$ area was removed from the rats. The content of PKC was monitored using a PKC assay kit, and graph displays the content of $\mathrm{PKC}$ in the $\mathrm{PO} / \mathrm{AH}$ tissues of rats following the intracerebroventricular injection of calphostin C. (B) Detection of rat body temperature. Treatment with LPS and a lateral ventricle injection of calphostin $\mathrm{C}$ at the same time increased body temperature significantly. (C) Following $4.5 \mathrm{~h}$ (LPS for $4 \mathrm{~h}$ and calphostin $\mathrm{C}$ for $4.5 \mathrm{~h}$ ), the $\mathrm{PO} / \mathrm{AH}$ area was removed from the rats. An injection of LPS into the lateral ventricle coupled with an injection of calphostin $\mathrm{C}$ at the same time reduced $\left(\mathrm{Ca}^{2+}\right)_{i}$ when compared with a simple injection of LPS. Data are presented as the mean \pm standard deviation. ${ }^{* *} \mathrm{P}<0.01$ vs. control; ${ }^{\wedge} \mathrm{P}<0.01$ vs. LPS. LPS, lipopolysaccharide; $\mathrm{PKC}$, protein kinase $\mathrm{C}$; cal, calphostin $\mathrm{C} ;\left(\mathrm{Ca}^{2+}\right)_{i}$, intracellular $\mathrm{Ca}^{2+}$ concentration; $\mathrm{PO} / \mathrm{AH}$, preoptic/anterior hypothalamus.

the body weight and a temperature rise were observed in mice with knock-out of TRPV1 gene. Steiner et al (18) discovered that the administration of a TRPV1 activator in abdominal cavities can inhibit skin vasoconstriction and thermogenesis to lower temperature.
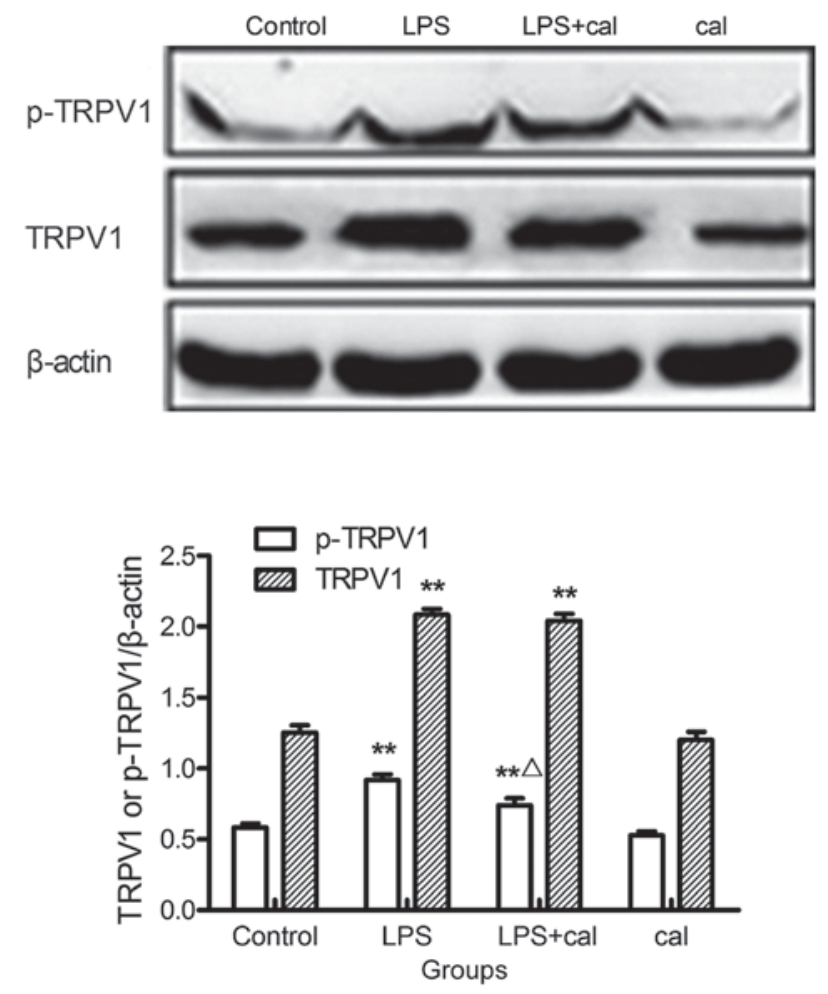

Figure 8. Effect of calphostin C on the expression of TRPV1 and p-TRPV1 in rats. (A) Following $4.5 \mathrm{~h}$ (LPS for $4 \mathrm{~h}$ and calphostin $\mathrm{C}$ for $4.5 \mathrm{~h}$ ), the $\mathrm{PO} / \mathrm{AH}$ area was removed from the rats. Western blotting revealed that an injection of LPS paired with a lateral ventricle injection of calphostin $\mathrm{C}$ at the same time decreased the expression of p-TRPV1. ${ }^{* *} \mathrm{P}<0.01$ vs. control; ${ }^{\Delta} \mathrm{P}<0.01$ vs. LPS. LPS, lipopolysaccharide; cal, calphostin C; TRPV1, transient receptor potential vanilloid; $\mathrm{p}-$, phosphorylated.

The study by Gavva et al (17) indicated that activation mechanisms of TRPV1 may include: i) The direct activation by endogenous substances in vivo on TRPV1 $(47)$; ii) the phosphorylation of TRPV1 channel protein for its sensitization and temperature regulation (34); and iii) phosphatidylinositol regulates TRPV1 (48), phospholipase cracks phosphatidylinosital biphosphate (PIP2) and releases the inhibition of TRPV1 structure (49).

Protein phosphorylation, a ubiquitous regulative way in organisms, plays an important role in the process of cell signal transduction. After phosphorylation, proteins show new functions in combination, regulation, catalysis and physical properties, etc.

The antibody to detect p-TRPV1 was p-TRPV1 with S800 locus in this study. TRPV1 has many protein kinase phosphorylation loci, but not every locus regulates and controls the TRPV1 temperature-sensitive gated channel. For example, PKC can phosphorylate TRPV1 S502, T704, S704, S800 and S820 loci in rats, but only S502 and S800 loci play a significant role in the regulation and control of the TRPV1 gated channel $(35,50,51)$. PKA can phosphorylate TRPV1 S116, T144, T370, S502, S774 and S800 loci, only S116, T144 and T370, however, show important regulation and control functions $(30,52,53)$. The article by Bhave et al (30) suggested that S502 and S800 were PKA phosphorylation loci as well as that of PKC. By patch clamp experiments, Wang et al discovered that high sensitivity of PKC-mediated TRPV1 on acid, capsaicin and thermal stimulation was mediated by 
different phosphorylation loci of PKC; and TRPV1 S800 was a multi-mode phosphorylation locus (24).

Calphostin C, a PKC inhibitor, can inhibit sulprostoneinduced fever (54). This is inconsistent with our results, as we have discovered that after fever caused by intraperitoneal injection of LPS and a brain ventricle injection of calphostin C, the temperature increase is much higher than the one in rats with a simple injection of LPS, as it may be associated with different fever inducing methods; and there are significantly different concentrations of drug use in our study. The concentration of calphostin $\mathrm{C}$ used in our experiment was $200 \mathrm{ng} / \mathrm{site}$ with an injection into the lateral ventricles, and the concentration of calphostin $\mathrm{C}$ used in the experiment of Zhou et al (54). Was $1 \mathrm{mg} / \mathrm{kg}$ with an injection into the lateral ventricles. Pre-treatment on PKC with calphostin C, a PKC inhibitor, can cause PKC to be inhibited; p-TRPV1 decreased, $\left(\mathrm{Ca}^{2+}\right)_{\mathrm{i}}$ in the $\mathrm{PO} / \mathrm{AH}$ area also diminished, TRPV1 activation decreased and meanwhile the temperature rose more, which indicated the negative regulation of TRPV1 on temperature weakened, resulting in a high temperature.

In 1987, Wachtel et al also proposed that the intraperitoneal injection of forskolin (a PKA agonist) in rats can cause the temperature to reduce (55). Studies have suggested that PKA can cause the TRPV1 sensitivity to rise (30,56-58). The article by Zhou et al (54) reported that H89, a PKA inhibitor, can inhibit sulprostone-induced fever, which is inconsistent with our results, and which may be correlated with the used drug dose. The dose of sulprostone used in the research by Zhou et al (54) was $1 \mathrm{mg} / \mathrm{kg}$, however, ours was $0.5,1,1.5 \mu \mathrm{g} / \mathrm{site}$ for the lateral ventricle injection. Our earlier experiment has confirmed that the expressions of TRPV1 and p-TRPV1 increased and there was a meantime PKA increase detected after LPS induced fever in the rats. In this experiment, the rats' lateral ventricles were first injected with different concentrations of the PKA inhibitor H89, and then LPS-caused fever was carried out. The results suggested that the rats' temperature was higher in the above group than that one in the simple LPS treatment group, and the expressions of TRPV1 and p-TRPV1 and $\left(\mathrm{Ca}^{2+}\right)_{\mathrm{i}}$ in the PO/AH area tissues decreased, which indicated that PKA after inhibition influenced TRPV1 phosphorylation, resulting in reducing TRPV1 activation and inhibiting the TRPV1 expressions.

The experiment demonstrated that LPS can induce the increased expression of TRPV1 and p-TRPV1, which is associated with many diseases $(59,60)$. By inhibiting the activity of PKA, CB1 inhibits TRPV1, reduces $\mathrm{Ca}^{2+}$ in cells and inhibits TRPV1-mediated currents, thereby reducing the inflammatory reactions and pains in the rats (61). It was also reported that the CB1 agonist inhibited the activity of TRPV1 via PKA, and reversed the thermal hyperalgesia induced by capsaicine (a TRPV1 agonist) (62). ET-1 promotes the phosphorylation of TRPV1 via PKC, which increases the activation of TRPV1 and causes pains (63). Therefore, the activation of TRPV1 and p-TRPV1 plays a critical role in many pathophysiological processes. However, ET-1 promotes the phosphorylation of TRPV1 via PKC, rather than PKA (63). In the present experiment, the inhibitors of PKC and PKA had similar effects, which caused fever through inhibiting the phosphorylation of TRPV1. Further studies are needed to identify the differences between these mechanisms of action.
There is a close relationship between central $\mathrm{Ca}^{2+}$ and temperature. The decrease of $\left(\mathrm{Ca}^{2+}\right)_{\mathrm{i}}$ in the brain ventricle can cause temperature rises (64). In this experiment, after injection of LPS, the expressions of TRPV1, p-TRPV1 and $\left(\mathrm{Ca}^{2+}\right)_{\mathrm{i}}$ in the $\mathrm{PO} / \mathrm{AH}$ area increased and the temperature rose; and after a meantime injection of the PKA inhibitor H89 (1 or $1.5 \mu \mathrm{g} / \mathrm{site})$ or the PKC inhibitor calphostin C (200 ng/site), the expressions of p-TRPV1 in the PO/AH area were inhibited, and meantime, $\left(\mathrm{Ca}^{2+}\right)_{\mathrm{i}}$ decreased, and the temperature rose more. All this suggested that p-TRPV1 plays an important part in the regulation of temperature, and p-TRPV1 makes TRPV1 more easily activated, resulting in $\left(\mathrm{Ca}^{2+}\right)_{\mathrm{i}}$ increasing to reduce the temperature; and PKA and PKC are important in the TRPV1 phosphorylation.

TRPV1 is also important in the maintenance of normal human temperature (19). Previous studies suggested that TRPV1 has a significant role in promoting inflammation in many diseases. In recent years, however, many studies have confirmed that TRPV1 shows protection in certain diseases, such as allergic contact dermatitis (26), and TRPV1 can protect the heart from ischemic reperfusion $(27,65)$. In addition to its protective effect, TRPV1 is also involved in normal physiological function activities, such as normal bladder functions (28), and normal vascular functions (29). Szolcsányi believed that TRPV1 mainly involves temperature regulation under the normal physiological condition, instead of playing a role under harmful heat stimulation (66).

This study observed that the lateral injection of H89 with 0.5 or $1 \mu \mathrm{g} / \mathrm{site}$ did not apparently influence the rat temperature, but the administration of H89 $1.5 \mu \mathrm{g} /$ site could cause the temperature to rise and $\left(\mathrm{Ca}^{2+}\right)_{\mathrm{i}}$ to reduce, the reasons of which may be related to the high concentration of H89 showing toxic action, or the need of a certain p-TRPV1 for maintaining the normal temperature. High concentrations of H89 cause TRPV1 desensitization, as is still unclear.

Phosphorylation is a major regulation mechanism of ionic channel activity. In vitro experiments have shown that TRPV1 phosphorylation is the major mechanism of TRPV1 activation (67). We speculate that exogenous or endogenous pyrogen in vivo promotes the body to display inflammatory responses and causes TRPV1 phosphorylation of thermoregulatory center under the action of inflammatory mediators, resulting in TRPV1 sensitivity, enhanced and gradually activated during temperature rising, thus playing a role in the negative regulation of temperature.

In this study, we found that H89 dihydrochloride hydrate and calphostin C lower the body temperature through TRPV1. However, this study has some limitations and there are further studies required to verify the mechanisms by which H89 and calphostin C work. TRPV1 specific antagonists should be used to inhibit TRPV1 and clarify its mechanism and to view the H89 and Cal's relationship with TRPV1 and the cooling effect of the phosphorylation of TRPV1.

\section{References}

1. Roth J: Endogenous antipyretics. Clin Chim Acta 371: 13-24, 2006.

2. Kluger MJ and Rothenburg BA: Fever and reduced iron: Their interaction as a host defense response to bacterial infection. Science 203: 374-376, 1979. 
3. Bartfai T and Conti B: Fever. ScientificWorldJournal 10: 490-503, 2010.

4. Demir F and Sekreter O: Knowledge, attitudes and misconceptions of primary care physicians regarding fever in children: A cross sectional study. Ital J Pediatr 38: 40, 2012.

5. Gentry C, Andersson DA and Bevan S: TRPA1 mediates the hypothermic action of acetaminophen. Sci Rep 5: 12771, 2015.

6. Foster J, Mauger AR, Govus A, Hewson D and Taylor L: Acetaminophen (paracetamol) induces hypothermia during acute cold stress. Clin Drug Investig 37: 1055-1065, 2017.

7. de Bont EG, Brand PL, Dinant GJ, van Well GT and Cals J: Risks and benefits of paracetamol in children with fever. Ned Tijdschr Geneeskd 158: A6636, 2014 (In Dutch).

8. Smith C and Goldman RD: Alternating acetaminophen and ibuprofen for pain in children. Can Fam Physician 58: 645-647, 2012.

9. Thiele K, Kessler T, Arck P,Erhardt A and Tiegs G: Acetaminophen and pregnancy: Short- and long-term consequences for mother and child. J Reprod Immunol 97: 128-139, 2013.

10. DuBOIS EF: Why are fever temperatures over 106 degrees F. rare? Am J Med Sci 217: 361-368, 1949.

11. Tatro JB: Endogenous antipyretics. Clin Infect Dis 5 (Suppl 31) S190-S201, 2000.

12. Caterina MJ, Schumacher MA, Tominaga M, Rosen TA Levine JD and Julius D: The capsaicin receptor: A heat-activated ion channel in the pain pathway. Nature 389: 816-824, 1997.

13. Garami A, Shimansky YP, Pakai E, Oliveira DL, Gavva NR and Romanovsky AA: Contributions of different modes of TRPV1 activation to TRPV1 antagonist-induced hyperthermia J Neurosci 30: 1435-1440, 2010.

14. Rowbotham MC, Nothaft W, Duan WR, Wang Y, Faltynek C, McGaraughty S, Chu KL and Svensson P: Oral and cutaneous thermosensory profile of selective TRPV1 inhibition by ABT-102 in a randomized healthy volunteer trial. Pain 152: 1192-1200, 2011.

15. Reilly RM, McDonald HA, Puttfarcken PS, Joshi SK, Lewis L, Pai M, Franklin PH, Segreti JA, Neelands TR, Han P, et al: Pharmacology of modality-specific transient receptor potential vanilloid-1 antagonists that do not alter body temperature J Pharmacol Exp Ther 342: 416-428, 2012.

16. Gavva NR, Bannon AW, Hovland DN Jr, Lehto SG, Klionsky L, Surapaneni S, Immke DC, Henley C, Arik L, Bak A, et al: Repeated administration of vanilloid receptor TRPV1 antagonists attenuates hyperthermia elicited by TRPV1 blockade J Pharmacol Exp Ther 323: 128-137, 2007.

17. Gavva NR, Bannon AW, Surapaneni S, Hovland DN Jr, Lehto SG, Gore A, Juan T, Deng H, Han B, Klionsky L, et al: The vanilloid receptor TRPV1 is tonically activated in vivo and involved in body temperature regulation. J Neurosci 27: 3366-3374, 2007.

18. Steiner AA, Turek VF, Almeida MC, Burmeister JJ, Oliveira DL, Roberts JL, Bannon AW, Norman MH, Louis JC, Treanor JJ, et al: Nonthermal activation of transient receptor potential vanilloid-1 channels in abdominal viscera tonically inhibits autonomic cold-defense effectors. J Neurosci 27: 7459-7468, 2007.

19. Gavva NR, Treanor JJ, Garami A, Fang L, Surapaneni S, Akrami A Alvarez F, Bak A, Darling M, Gore A, et al: Pharmacological blockade of the vanilloid receptor TRPV1 elicits marked hyperthermia in humans. Pain 136: 202-210, 2008.

20. Hori T: Capsaicin and central control of thermoregulation. Pharmacol Ther 26: 389-416, 1984.

21. Caterina MJ, Leffler A, Malmberg AB, Martin WJ, Trafton J, Petersen-Zeitz KR, Koltzenburg M, Basbaum AI and Julius D: Impaired nociception and pain sensation in mice lacking the capsaicin receptor. Science 288: 306-313, 2000.

22. Iida T, Shimizu I, Nealen ML, Campbell A and Caterina M: Attenuated fever response in mice lacking TRPV1. Neurosci Lett 378: 28-33, 2005.

23. Szelényi Z, Hummel Z, Szolcsányi J and Davis JB: Daily body temperature rhythm and heat tolerance in TRPV1 knockout and capsaicin pretreated mice. Eur J Neurosci 19: 1421-1424, 2004

24. Wang S, Joseph J, Ro JY and Chung MK: Modality-specific mechanisms of protein kinase C-induced hypersensitivity of TRPV1: S800 is a polymodal sensitization site. Pain 156 931-941, 2015

25. Honore P, Chandran P, Hernandez G, Gauvin DM, Mikusa JP, Zhong C, Joshi SK, Ghilardi JR, Sevcik MA, Fryer RM, et al: Repeated dosing of ABT-102, a potent and selective TRPV1 antagonist, enhances TRPV1-mediated analgesic activity in rodents, but attenuates antagonist-induced hyperthermia. Pain 142: 27-35, 2009.
26. Bánvölgyi A, Pálinkás L, Berki T, Clark N, Grant AD, Helyes Z, Pozsgai G, Szolcsányi J, Brain SD and Pintér E: Evidence for a novel protective role of the vanilloid TRPV1 receptor in a cutaneous contact allergic dermatitis model. J Neuroimmunol 169 86-96, 2005.

27. Wang L and Wang DH: TRPV1 gene knockout impairs postischemic recovery in isolated perfused heart in mice. Circulation 112: 3617-3623, 2005

28. Birder LA, Nakamura Y, Kiss S, Nealen ML, Barrick S, Kanai AJ, Wang E, Ruiz G, De Groat WC, Apodaca G, et al: Altered urinary bladder function in mice lacking the vanilloid receptor TRPV1. Nat Neurosci 5: 856-860, 2002.

29. Tóth A, Czikora A, Pásztor ET, Dienes B, Bai P, Csernoch L, Rutkai I, Csató V, Mányiné IS, Pórszász R, et al: Vanilloid receptor-1 (TRPV1) expression and function in the vasculature of the rat. J Histochem Cytochem 62: 129-144, 2014.

30. Bhave G, Zhu W, Wang H, Brasier DJ, Oxford GS and Gereau RW IV: cAMP-dependent protein kinase regulates desensitization of the capsaicin receptor (VR1) by direct phosphorylation. Neuron 35: 721-731, 2002.

31. De Petrocellis L, Harrison S, Bisogno T, Tognetto M, Brandi I, Smith GD, Creminon C, Davis JB, Geppetti P and Di Marzo V: The vanilloid receptor (VR1)-mediated effects of anandamide are potently enhanced by the cAMP-dependent protein kinase. J Neurochem 77: 1660-1663, 2001

32. Hu HJ, Bhave G and Gereau RW IV: Prostaglandin and protein kinase A-dependent modulation of vanilloid receptor function by metabotropic glutamate receptor 5: Potential mechanism for thermal hyperalgesia. J Neurosci 22: 7444-7452, 2002.

33. Koda K, Hyakkoku K, Ogawa K, Takasu K, Imai S, Sakurai Y, Fujita M, Ono H, Yamamoto M, Fukuda I, et al: Sensitization of TRPV1 by protein kinase $\mathrm{C}$ in rats with mono-iodoacetate-induced joint pain. Osteoarthritis Cartilage 24: 1254-1262, 2016.

34. Premkumar LS and Ahern GP: Induction of vanilloid receptor channel activity by protein kinase C. Nature 408: 985-990, 2000.

35. Bhave G, Hu HJ, Glauner KS, Zhu W, Wang H, Brasier DJ, Oxford GS and Gereau RW IV: Protein kinase C phosphorylation sensitizes but does not activate the capsaicin receptor transient receptor potential vanilloid 1 (TRPV1). Proc Natl Acad Sci USA 100: 12480-12485, 2003.

36. Chung MK, Lee J, Joseph J, Saloman J and Ro JY: Peripheral group I metabotropic glutamate receptor activation leads to muscle mechanical hyperalgesia through TRPV1 phosphorylation in the rat. J Pain 16: 67-76, 2015.

37. Liu J, Du J, Yang Y and Wang Y: Phosphorylation of TRPV1 by cyclin-dependent kinase 5 promotes TRPV1 surface localization, leading to inflammatory thermal hyperalgesia. Exp Neurol 273: 253-262, 2015

38. Jendryke T, Prochazkova M, Hall BE, Nordmann GC, Schladt M, Milenkovic VM, Kulkarni AB and Wetzel CH: TRPV1 function is modulated by Cdk5-mediated phosphorylation: Insights into the molecular mechanism of nociception. Sci Rep 6: 22007, 2016.

39. Cesare P and McNaughton P: A novel heat-activated current in nociceptive neurons and its sensitization by bradykinin. Proc Natl Acad Sci USA 93: 15435-15439, 1996.

40. Cesare P, Dekker LV, Sardini A, Parker PJ and McNaughton PA: Specific involvement of PKC-epsilon in sensitization of the neuronal response to painful heat. Neuron 23: 617-624, 1999.

41. Dai Y, Moriyama T, Higashi T, Togashi K, Kobayashi K, Yamanaka H, Tominaga M and Noguchi K: Proteinase-activated receptor 2-mediated potentiation of transient receptor potential vanilloid subfamily 1 activity reveals a mechanism for proteinase-induced inflammatory pain. J Neurosci 24: 4293-4299, 2004.

42. Hong S and Wiley JW: Early painful diabetic neuropathy is associated with differential changes in the expression and function of vanilloid receptor 1. J Biol Chem 280: 618-627, 2005.

43. Xiao X, Zhao XT, Xu LC, Yue LP, Liu FY, Cai J, Liao FF, Kong JG, Xing GG, Yi M and Wan Y: Shp-1 dephosphorylates TRPV1 in dorsal root ganglion neurons and alleviates CFA-induced inflammatory pain in rats. Pain 156: 597-608, 2015.

44. Tóth A, Boczán J, Kedei N, Lizanecz E, Bagi Z, Papp Z, Edes I, Csiba L and Blumberg PM: Expression and distribution of vanilloid receptor 1 (TRPV1) in the adult rat brain. Brain Res Mol Brain Res 135: 162-168, 2005.

45. Alawi KM, Aubdool AA, Liang L, Wilde E, Vepa A, Psefteli MP, Brain SD and Keeble JE: The sympathetic nervous system is controlled by transient receptor potential vanilloid 1 in the regulation of body temperature. FASEB J 29: 4285-4298, 2015. 
46. Garami A, Pakai E, Oliveira DL, Steiner AA, Wanner SP, Almeida MC, Lesnikov VA, Gavva NR and Romanovsky AA: Thermoregulatory phenotype of the Trpv1 knockout mouse: Thermoeffector dysbalance with hyperkinesis. J Neurosci 31: 1721-1733, 2011.

47. Van Der Stelt M and Di Marzo V: Endovanilloids. Putative endogenous ligands of transient receptor potential vanilloid 1 channels. Eur J Biochem 271: 1827-1834, 2004.

48. Rohacs T: Phosphoinositide regulation of TRPV1 revisited. Pflugers Arch 467: 1851-1869, 2015.

49. Chuang HH, Prescott ED, Kong H, Shields S, Jordt SE, Basbaum AI, Chao MV and Julius D: Bradykinin and nerve growth factor release the capsaicin receptor from $\operatorname{PtdIns}(4,5)$ P2-mediated inhibition. Nature 411: 957-962, 2001.

50. Numazaki M, Tominaga T, Toyooka $H$ and Tominaga $M$ : Direct phosphorylation of capsaicin receptor VR1 by protein kinase Cepsilon and identification of two target serine residues. J Biol Chem 277: 13375-13378, 2002.

51. Huang J, Zhang X and McNaughton PA: Modulation of temperature-sensitive TRP channels. Semin Cell Dev Biol 17: 638-645, 2006.

52. Mohapatra DP and Nau C: Regulation of $\mathrm{Ca}^{2+}$-dependent desensitization in the vanilloid receptor TRPV1 by calcineurin and cAMP-dependent protein kinase. J Biol Chem 280: 13424-13432, 2005.

53. Jeske NA, Patwardhan AM, Gamper N, Price TJ, Akopian AN and Hargreaves KM: Cannabinoid WIN 55,212-2 regulates TRPV1 phosphorylation in sensory neurons. J Biol Chem 281: 32879-32890, 2006.

54. Zhou J, Li CH, Huo HR, Kang XL, Li LF, Jiang N and Jiang TL: Effect of guizhi decoction on PKA and PKC activities of hypothalamus in fever rats. Zhongguo Zhong Yao Za Zhi 31: 66-69, 2006 (In Chinese).

55. Wachtel H, Löschmann PA, Schneider HH and Rettig KJ: Effects of forskolin on spontaneous behavior, rectal temperature and brain cAMP levels of rats: Interaction with rolipram. Neurosci Lett 76: 191-196, 1987.

56. Distler C, Rathee PK, Lips KS, Obreja O, Neuhuber W and Kress M: Fast $\mathrm{Ca}^{2+}$-induced potentiation of heat-activated ionic currents requires cAMP/PKA signaling and functional AKAP anchoring. J Neurophysiol 89: 2499-2505, 2003.

57. Mohapatra DP and Nau C: Desensitization of capsaicin-activated currents in the vanilloid receptor TRPV1 is decreased by the cyclic AMP-dependent protein kinase pathway. J Biol Chem 278: 50080-50090, 2003
58. Rathee PK, Distler C, Obreja O, Neuhuber W, Wang GK, Wang SY, Nau C and Kress M: PKA/AKAP/VR-1 module: A common link of Gs-mediated signaling to thermal hyperalgesia. J Neurosci 22: 4740-4745, 2002.

59. Chan CL, Facer P, Davis JB, Smith GD, Egerton J, Bountra C, Williams NS and Anand P: Sensory fibres expressing capsaicin receptor TRPV1 in patients with rectal hypersensitivity and faecal urgency. Lancet 361: 385-391, 2003.

60. Facer P, Knowles CH, Tam PK, Ford AP, Dyer N, Baecker PA and Anand P: Novel capsaicin (VR1) and purinergic (P2X3) receptors in Hirschsprung's intestine. J Pediatr Surg 36: 1679-1684, 2001.

61. Yang Y, Yang H, Wang Z, Varadaraj K, Kumari SS, Mergler S, Okada Y, Saika S, Kingsley PJ, Marnett LJ and Reinach PS: Cannabinoid receptor 1 suppresses transient receptor potential vanilloid 1-induced inflammatory responses to corneal injury. Cell Signal 25: 501-511, 2013.

62. Patwardhan AM, Jeske NA, Price TJ, Gamper N, Akopian AN and Hargreaves KM: The cannabinoid WIN 55,212-2 inhibits transient receptor potential vanilloid 1 (TRPV1) and evokes peripheral antihyperalgesia via calcineurin. Proc Natl Acad Sci USA 103: 11393-11398, 2006.

63. Plant TD,Zöllner C, Kepura F, Mousa SS, Eichhorst J, Schaefer M, Furkert J, Stein C and Oksche A: Endothelin potentiates TRPV1 via ETA receptor-mediated activation of protein kinase C. Mol Pain 3: 35, 2007.

64. Palmi M and Sgaragli G: Hyperthermia induced in rabbits by organic calcium antagonists. Pharmacol Biochem Behav 34: 325-330, 1989.

65. Gross ER, Urban TJ, Hsu AK, Qvit N, Gross GJ and Mochly-Rosen D: TRPV1 mediates remote and direct cardioprotection. Circ Res 113: A213, 2013.

66. Szolcsányi J: Effect of capsaicin on thermoregulation: An update with new aspects. Temperature (Austin) 2: 277-296, 2015.

67. Lee J, Chung MK and Ro JY: Activation of NMDA receptors leads to phosphorylation of TRPV1 S800 by protein kinase C and A-Kinase anchoring protein 150 in rat trigeminal ganglia. Biochem Biophys Res Commun 424: 358-363, 2012.

This work is licensed under a Creative Commons Attribution-NonCommercial-NoDerivatives 4.0 International (CC BY-NC-ND 4.0) License. 